\title{
System Dynamic Approach to Improve Emergency Response in Humanitarian Logistics in Indonesia
}

\author{
Gregorios Yogas Sundara ${ }^{1 *}$, Paulina Kus Ariningsih ${ }^{1}$
}

\begin{abstract}
Volatile and vulnerable conditions during disaster relief cause many problems in the coordination of aid replenishments. Research states that partnership improves coordination, reducing the uncertainty condition along the supply chain, including replenishment. This paper aims to fulfill the research gap by examining the impact of partnership in the disaster relief process. The model's dynamic characteristics were examined by modifying the beer distribution game through Vensim PLE Plus. The model had been validated and verified with the West Java Regional Disaster Management Authority (BPPD). The simulation was run for two types of products: repetitive demand (food package) and one-time demand (blanket). Total cost, bullwhip effect, and total distribution time for each scenario are then compared. The simulation results show that the proposed scenario, developed based on blockchain usage on the partnership system, can reduce the total distribution time by about $43 \%$ for the blanket and $27 \%$ for the food package. Meanwhile, the total reducing cost for blankets is $29 \%$ and $13 \%$ for food packages. However, on the other side, the partnership system had aggravated the bullwhip effect.
\end{abstract}

Keywords: Humanitarian logistics, replenishment, system dynamic, blockchain.

\section{Introduction}

Thomas and Kopczak [1] defined humanitarian supply chains as managing and designing methods of delivering disaster relief material such as food, water, sanitation, and a refugee camp for disaster impacted areas, which are mostly unattainable or remote. The humanitarian supply chain's difficulties and challenges are the dynamic and variability aspects of the type and number of demands and the disaster event's time and location [2]. Arminas [3] had publicized that fulfilling the demand of victims in the humanitarian supply chain is very vague because the amount, time, and location of demand deliveries are unknown. Therefore, it is crucial to understand and agile in adjusting the needs with the type of disaster event, geographical areas, access to the impacted areas, and damage catastrophes. In such a dynamic situation, one can be trapped in a trade-off between cost efficiency and a short decision-making period. Thus, there are three essential aspects of performance measurement on humanitarian logistics: resource, output, and flexibility [2]. Resource refers to every cost, such as supplies, distribution costs, and inventtory holding costs. The output refers to response time and the amounts of items that could be provided and distributed. Meanwhile, flexibility defines as the volume and variety of items for fulfilling demand.

1 Faculty of Engineering, Industrial Engineering Department, Universitas Katolik Parahyangan, Л. Ciumbuleuit 94, Bandung 40141, Indonesia. Email gregorios_20180019@unpar.ac.id, paulina.ariningsih@unpar.ac.id

* Corresponding author
One of the supply chain strategies that could increase a supply chain system's performance under dynamic and volatile conditions is the strategy of partnerships [4]. The partnership entails an effective coordination system for any supply chain management. According to Tomasini [5], partnerships could be useful when all participants agree to work together, and it could be misplaced whenever a clearly defined need between supplier and customer appears. According to Comes and Walle [6], the challenge of a supply chain system is how to share the information between parties. Some security policies and risk considerations limit a party to share their information with the other in several cases. According to Angulo, et al. [7], it is said that the concept of the partnership through Vendor Management Inventory (VMI) could allow vendors to puts direct replenishment to buyers without waiting for order first, which will reduce the delay time for ordering and shorten the replenishment time to the buyer [8]. Sharing information between parties will be easier to apply because it could be transparent and secure using blockchain's powerful mechanism [9]. By the strength points of partnership, partnerships are expected to improve the humanitarian logistics sector's performance, especially in demand uncertainty.

The researcher had worked on several strategies to overcome the humanitarian logistics' vulnerability. Lodree [10] used the analytic approach of economic order quantity with minimax decision rules to analyze pre-disaster logistics for emergency supplies. The limitation of that research is on the assumptions built just based on the theoretical approach, thus lack 
of implications on the specific practical system. Furthermore, Habib et al. [11] had noted that there are some potential Humanitarian Supply Chain research areas on developing practical and feasible simulation models. Iakovou et al. [12] tried to solve the uncertainty and dynamic problems on humanitarian logistics by DES (Discrete Event Simulation); however, the simulated variables on DES only hold a correlation relationship without causality. Iakovou et $a l$. [12] also suggested a simulation-based to ensure the cost efficiency and time-to-recovery efficiency of humanitarian aid relief.

On the other hand, Sterman [13] confirmed that system dynamics simulation is very suitable in describing systems' dynamics over time easily. Bimantino [14] stated that system dynamics is a method to study some feedback scheme from a complex system. The used system dynamic simulation to understand the behavior of systems had been applied to several studies: IOT infrastructure in pharmacy industry [15], salacca-pondoh's business [14], airport characterization in hub-and-spoke networks [16]. Besiou et al. [17] had managed to use system dynamics for modeling humanitarian logistics. Beer game simulation is a system dynamic simulation that mimics a simple supply chain [13]. The system dynamic simulation may depict the causal effect relationship on a system by system thinking. Thus, it is advantageous to be used for assessing a particular policy on a system. The beer game's system dynamic simulation is classical to assess the partnership strategy's impact in the business supply chain and not yet implied for humanitarian logistics. It is expected that the system dynamic model based on beer game modification is suitable to describe the condition of the disaster relief system in the humanitarian logistics, especially in the emergency response phase, the first and most crucial seven days after the disaster hit a location.

Even though Indonesia already has a strategic management plan for disaster risk reduction, the urgency of having a virtuous response phase high risk of disaster in Indonesia is reinforced by the high degree of disaster risk and exposure and the vulnerability of the particular humanitarian logistics. According to data released by the Indonesian National Disaster Management website, the BPBD (Indonesian National Disaster Management Agency) has recorded 1970 disaster events, on average, which occur each year from 2009 to 2019 in Indonesia. Based on the data, on average, $51 \%$ of victims died in a single disaster, and five to 6 disaster events could happen in a single day. When the tsunami hit Lombok on 5 August 2018, it is said that the disaster victims suffered from a lack of water and tarpaulin [18]. According to jawapos.com [19], some regions did not get any goods in that disaster event. The distribution system could not reach remote areas. The Commander of Lombok Disaster Relief Central Post said a lack of disaster relief for victims and the aids were run out instantly. There is a minimal reference available so far about the strategic assessment on the partnership, especially on assessing the supply chain's dynamic situation, especially in Indonesia's humanitarian logistics. Hence, the research question addressed in this article is, "What is the impact of partnership strategy toward the performance of disaster emergency response systems in Indonesia?"

This article is structured into four major sections. Firstly, the introduction describes the background of this research. The second section describes the methodology of the research. The third section describes the research result; it explains the current emergency response system, then the built of stock and flow diagram, with the performance comparison between the current system and the proposed partnership system and ends with a discussion. The conclusion would be the last section of the research.

\section{Methods}

The methodology of this research follows the stage in Reyes [20]. This study's first step is the concepttualization stage, where material and information flow on the current replenishment system is described. The flow of material and information should be described first to be the basis of this research to build the current system model known as problem structuring [16]. After the expert verifies the problem structure model, the data is collected, and a causal loop diagram is built [16] to guide the real-world problem situation [20]. A stock and flow diagram is built on the formulation stage to apply system thinking ideas in the model, as suggested in Senge [21]. Kim [22] stated that a stock and flow diagram is a tool that could represent the structure of a system dynamic. According to Zakery et al. [23], stock and flow diagrams can be used as the basis for analyzing and improving the strategic alignment of firms' resources. Stock and flow diagrams could also describe the dynamic model of delays in emergency departments [24].

The stock and flow diagram of the current system is built under the scope and assumption of beer game simulation. Stock and flow diagrams could describe the changes in rate in a periodical view. The stock in this model is the variable that is used as an inventory of the materials. The flow in this model is whatever goes in or out from the inventory of the materials.

The stock and flow diagram are built for two types of products, which represent different types of aids: 


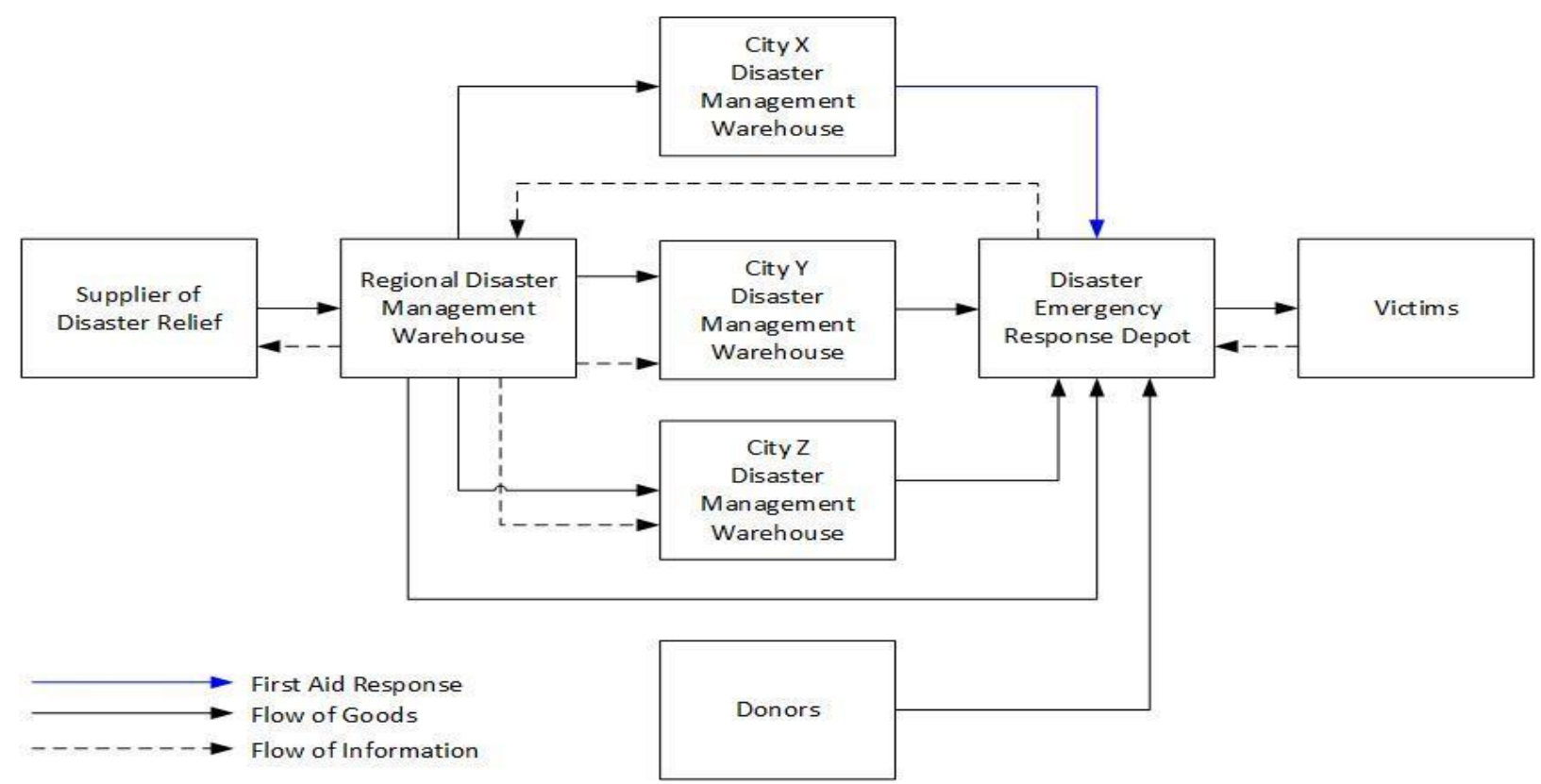

Figure 1. Flow process diagram of current system

blanket (one-time delivery per victim) and food (multi delivery per victim). Blankets, necessary hygiene equipment, and sleeping mats have the same characteristic. Those types of goods are delivered onetime per victim during the disaster relief phase. Meanwhile, food should be delivered frequently during the phases since every victim needs a food supply for more than a single time. We consider both types of products to make sure the rigorous of our proposed solution. The stock and flow diagram are validated by the logistic manager of Regional Disaster Management of West Java by ensuring the model matches the real condition. Since the data used are hypothetical, the simulation model's validation is also done by the logistic manager of Regional Disaster Management of West Java's judgement and comparing the pattern on the simulation result graph to the beer distribution game's pattern.

Two simulation scenarios are performed on the testing stage based on the disaster relief period's stock and flow diagram. The first scenario is intended to understand the emergency response phase's performance for seven days of the disaster relief when the demand volatile is low. The second simulation scenario is performed for seven days in the emergency response phase plus high volatile demand on the seven days after. In this scenario, there is an aftershock disaster after the disaster relief phase that triggers a rise in demand instantly. Both scenarios are developed to represent the current condition mentioned in the interview with the logistic manager of Regional Disaster Management of West Java, Indonesia.
For each scenario, two models are developed to represent current practice and partnership models. The model of the system is limited to the Regional Disaster Management's direct scope of influence. Analysis of the partnership (suggestion) model is done by literature study, best practices of business logistics, and by understanding disaster relief replenishment systems' structure. Based on the vision of using a partnership system, a new stock and flow diagram are developed, and simulation is performed to predict the system's behavior. Performance measurement parameters such as cost, time, bullwhip effect index, and inventory backlog are then analyzed by simulating Vensim PLE Plus, as suggested by Akhlaghinia et al. [15]. Vensim PLE Plus is a fully functional software package from the Ventana system for simulating the system dynamics [15]. The dynamic system simulation is performed to develop to study the system's response to the demand, managerial implication, understanding research limitations, and future potential research.

\section{Model Development}

Indonesia's disaster relief distribution system involves many parties such as suppliers, national disaster management, regional disaster management, donors (including communities), and the victims [25]. All parties have an essential role in ensuring that the disaster relief logistics system is running smoothly. For example, the government has coordination for aid distribution between national and regional disaster management and society. As stated by government regulation (constitution) UU no 24, 2007 about Disaster Management, the government would 
finance the disaster management and coordinate or control the disaster aids as per its scope of control; for example, the District Government shall manage its district.

The flow of goods and information diagram for the current system verified by an expert of BPBD is seen in Figure 1. In the figure, victims are supplied by disaster emergency response, which is erected by nearest city $\mathrm{X}$. Thus, first aid is coming from the city $\mathrm{X}$ as well. After the safety stock of city $\mathrm{X}$ is empty, aid support will be given through the next nearest city, $\mathrm{Y}$ and Z. All cities are supplied by regional disaster management offices in the capital city of the province. Donors may send the aid directly to the disaster emergency response post. Therefore, the partnership would take place between the supplier and regional disaster management.

\section{Causal Loop Diagram}

According to Kim [22], a causal loop diagram is a tool that can explain how the dynamic and interconnected are happen on a system. In this study, causal loop diagrams were made to understand the problems that occur in the system dynamic of providing natural disaster relief and defining the initial stock and flow diagrams' initial model. There were three steps to explore the causal loop diagram. It begins by describing the relationship between suppliers and Regional Disaster Management. The second step is describing the relation between Regional Disaster Management and Impacted City. The last step is combining the first two relations and exploring the other causal variable. The causal loop diagram for the current system is as seen in Figure 2.

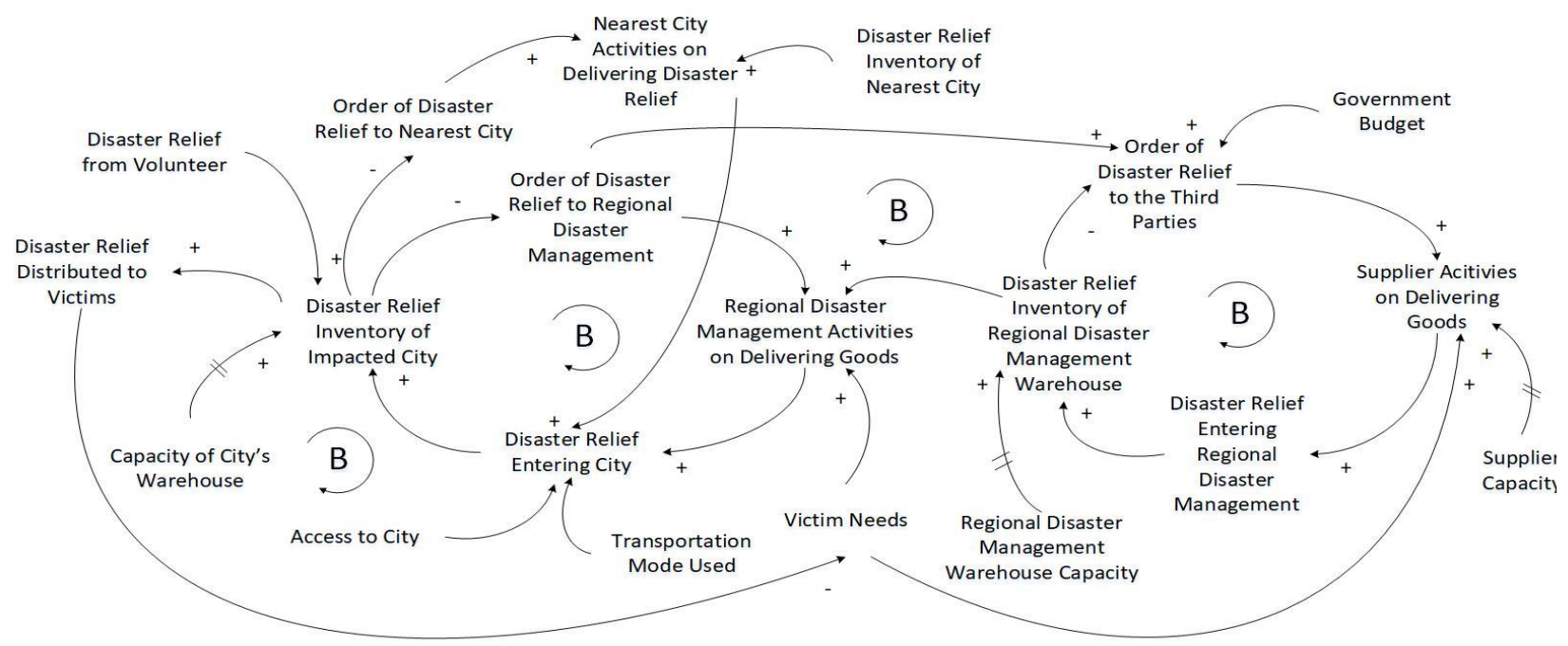

Figure 2. Causal loop diagram of the current system

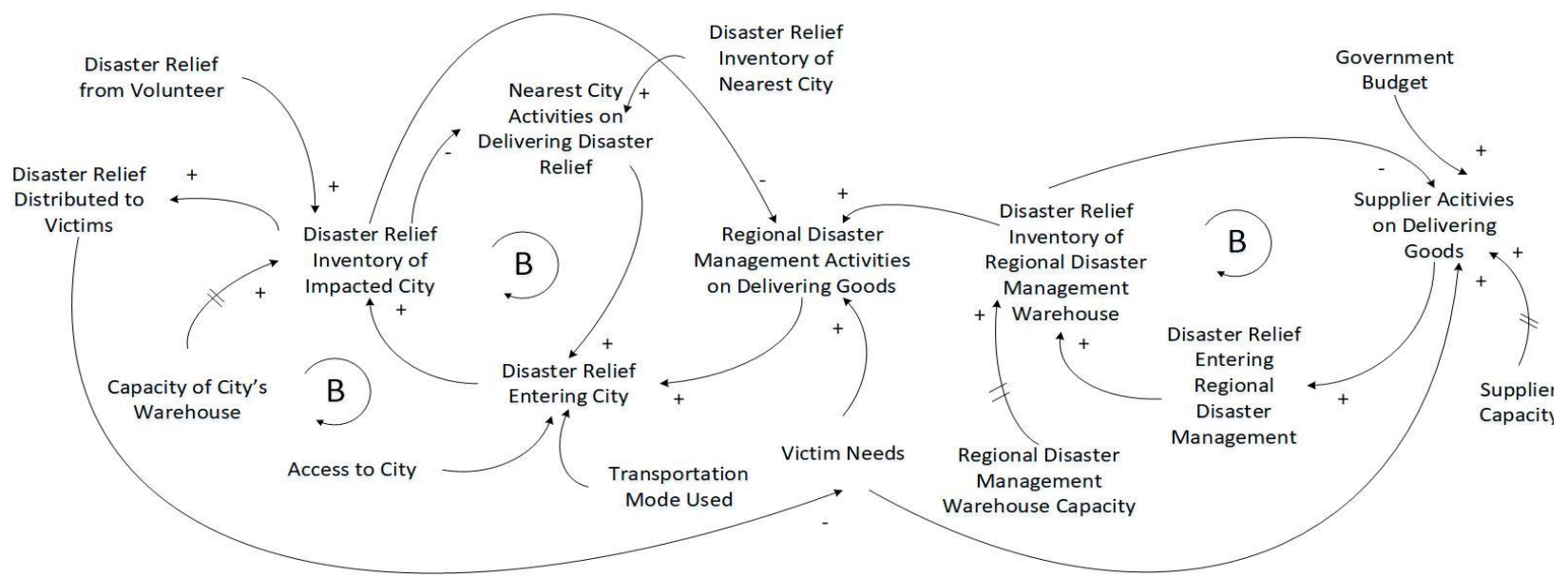

Figure 3. Causal loop diagram of the partnership system 
There are four balancing loops on the Causal Loop Diagram (Figure 2). The first loop depicts the ordering process of the Regional Disaster Management to the third party or supplier. The number of orders is limited to warehouse capacity, government budget, and supplier capacity. Meanwhile, the second loop describes the process delivery of the aids from Regional Disaster Management to the impacted city's warehouse. The third loop appears because of the causal effect of the first and second loop. The fourth loop describes how the impacted city's warehouse tries to fulfill all the victim's needs. There is no direct interaction between officers at the disaster site and disaster relief suppliers. It may take a long time to order.

The causal loop diagram of the proposed partnership system is, as seen in Figure 3. On the proposed causal loop diagram, partnerships are applied to maintain relationships with suppliers as one of the support systems in the application of blockchain. Blockchain has the advantages of undeletable and transparency of records. Therefore, by implementing the private blockchain system, every data input, transaction, and movement of goods would be recorded, and every party could see it as long as there is an internet [26]. The procurement approval bureaucracy of disaster victims would also shorten the administration process and impact reducing ordering times in the supply chain as a whole system [26]. The system would process the data of needs and the amount of stock in each party in real-time. Therefore, the supplier can immediately see the system's updates and supply goods as soon as possible. Even Regional Disaster Management no longer needs to place an order of disaster relief to the suppliers because the supplier will push the goods directly when they update information about victim needs. There will be no lead time in ordering disaster relief.

\section{Stock and Flow Diagram}

The stock and flow diagram for the current system is depicted in Figure 4, while the stock and flow diagram for the partnership system is depicted in Figure 5.

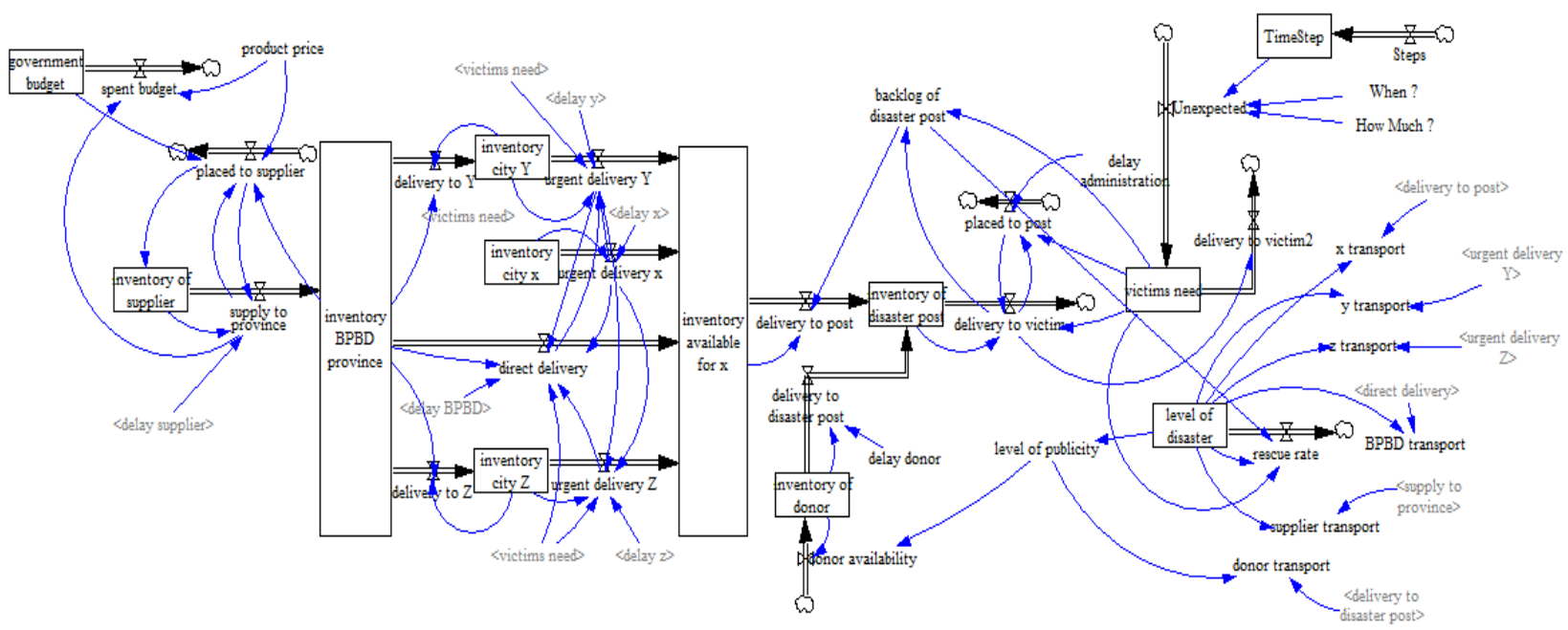

Figure 4. Stock and flow diagram of the current system

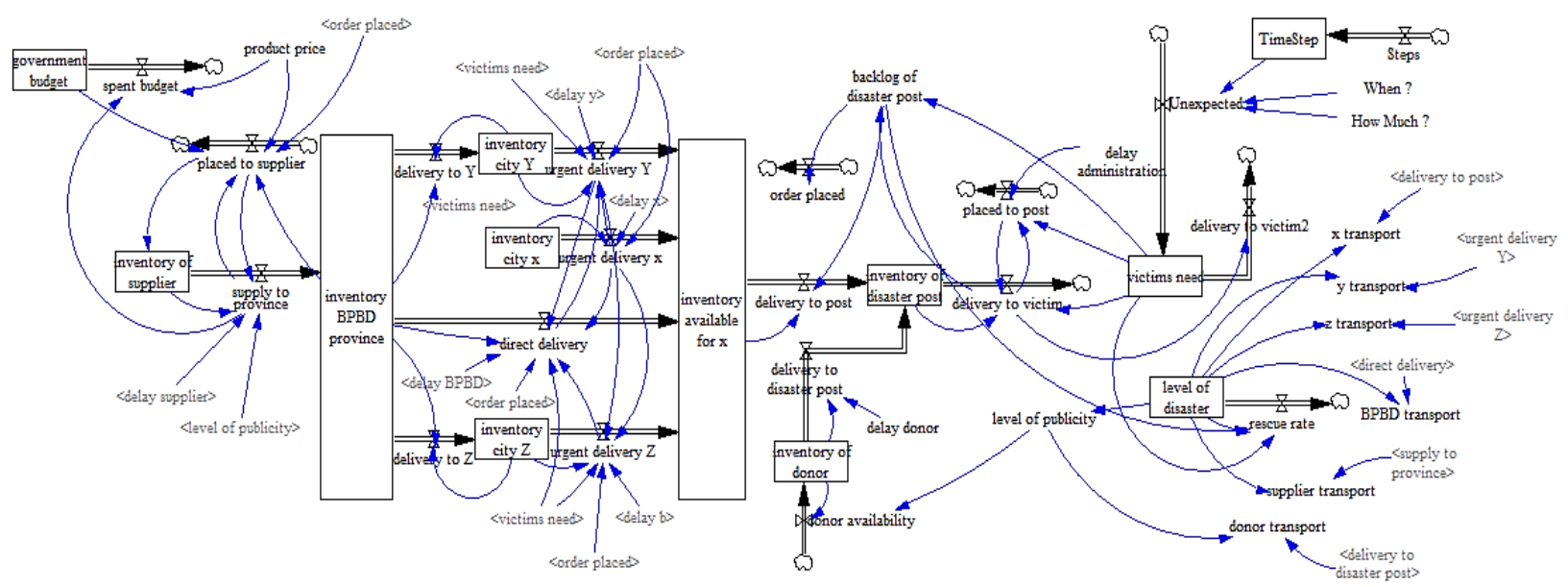

Figure 6. Stock and flow diagram of the partnership system 
Table 1. Hypothetical data for the proposed model

\begin{tabular}{|c|c|c|c|c|c|}
\hline \multirow{2}{*}{ Inventory } & \multicolumn{2}{|c|}{$\begin{array}{c}\text { Pre-disaster } \\
\text { inventory (unit) }\end{array}$} & \multirow{2}{*}{$\begin{array}{l}\text { Distance to } \\
\text { disaster } \\
\text { post } \\
\text { (Hours) }\end{array}$} & \multicolumn{2}{|c|}{ Demand (unit) at $\mathrm{t}=0$} \\
\hline & $\begin{array}{c}\text { Food } \\
\text { package }\end{array}$ & Blanket & & $\begin{array}{l}\text { Food } \\
\text { package }\end{array}$ & Blanket \\
\hline$\overline{\text { City Y }}$ & 75 & 12 & 2.9 & \multirow{5}{*}{2250} & \multirow{5}{*}{400} \\
\hline City Z & 70 & 11 & 3.6 & & \\
\hline City X & 93 & 15 & 1.7 & & \\
\hline $\begin{array}{l}\text { BPBD } \\
\text { Province }\end{array}$ & 617 & 100 & 5.9 & & \\
\hline $\begin{array}{l}\text { Disaster } \\
\text { Post }\end{array}$ & 0 & 0 & 0 & & \\
\hline
\end{tabular}

Table 2. Scenario description

\begin{tabular}{ll}
\hline Scenario & Description \\
\hline F1 (Food 1) & $\begin{array}{l}\text { Demand for food is already assessed at } \mathrm{t}=0 \\
\text { of } 2250 \text { food package, and there is no surge } \\
\text { in demand. }\end{array}$ \\
B1 (Blanket 1) & $\begin{array}{l}\text { Demand for blanket is already assessed at } \\
\mathrm{t}=0 \text { of } 400 \text { blanket, and there is no surge in } \\
\text { demand. } \\
\text { Demand for food is already assessed at } \mathrm{t}=0 \\
\text { of } 2250 \text { food package, and there is surge in } \\
\text { demand at } \mathrm{t}=72 \text { of } 1000 \text { food package. } \\
\text { Demand for blanket is already assessed at } \\
\mathrm{t}=0 \text { of } 400 \text { blanket, and there is surge in } \\
\text { demand at } \mathrm{t}=72 \text { of } 300 \text { blanket. }\end{array}$ \\
\hline
\end{tabular}

The stock and flow diagram was developped based on a hypothetical case of disaster verified by experts of BPBD. This research assumes that the disaster event's impact is on the middle range scale, not a catastrophic one.

It is supposed that City X is surrounded by City Y and City $\mathrm{Z}$ and was located away from the capital of its province. Each city had prepared a pre-disaster inventory. When the disaster hit a particular area, Regional Disaster Management assessed the demand of all victims. Then the BPBD officer would send the information of the victim's needs to be fulfilled by inventory City X. Whenever inventory City $\mathrm{X}$ is empty, aid will be given from inventory City Y and City Z, and the inventory of BPBD Province will be pulled whenever nearest city's inventory runs out. The information of demands and distribution of aids to the victim are managed by disaster post at the impacted area. There is an amount of delay administration during distributing the materials (food or blanket). The administration process is necessary to ensure that each victim would get the right items. If the inventory of BPBD Province is empty or hitting reorders point, then the BPBD would order to the supplier under government (province) budget or funds.

The data that is used in the stock and flow model is hypothetical, as in Table 1 . The data consider five factors such as pre-disaster inventory, the number of demands, delay time on distributing materials, the distance between suppliers and impacted areas, and publicity level of disaster events. The pre-disaster inventory data is collected using random numbers on five criteria (Indonesian Risk Disaster Index, population number, the chain of control, inventory capacity, and human resource capacity). The limitations of random numbers are determined using the secondary data from Regional Disaster Management of West Java. Supposed that the number of victims is determined at $0.01 \%$ population of City X. The demand for food is three times daily per victim, while the blanket demand is only 1 per victim. The distance between the inventory of City X and the impacted area is random between $0-20 \mathrm{~km}$. Meanwhile, the distance between the inventory of City Y / City Z and the impacted area is determined by using random numbers between $17-72 \mathrm{~km}$, and the distance between BPBD Province and the impacted area is determined using random numbers between $20-184 \mathrm{~km}$. The limit of random numbers depends on the minimum distance and maximum distance between both areas, as in the reality of West Java Province, Indonesia.

The delay time of distribution between parties is determined using a random number between 1-2 hours. This figure is decided based on the interview with the logistics manager of Regional Disaster Management of West Java. The publicity level is determined at one at period 0 and will decrease as soon as the demand is fulfilled. The model is run for 14 days horizon during the emergency response phase as suggested by West Java Regional Disaster Management's officer. Time $=0$ is started right after the disaster happens, which is the emergency response phase. The period is calculated in hours. Thus, the flow of distributed materials and stock updates of each inventory could be defined every hour.

The stock and flow diagram of the partnership system is depicted in Figure 5. The stock and flow are able to describe the disaster relief material for each food package and blanket. The purpose of the partnership system is to reduce order delay time by getting information quickly. It is as defined in Figure 5.

The difference between the stock and flow of the current system and partnership system is located on order placed system; specifically, the order information would be sent directly to the suppliers. Using a partnership system, as long as the suppliers had enough logistics, the victim's needs will be fulfilled in the shortest time. The cost performance on both scenarios is determined by two cost components: delivery cost, and inventory cost, as stated by the logistic manager of Regional Disaster Manager of West Java. Beamon et al. [2] also mentioned that costs incurred due to the transfer and storage of material could be the Humanitarian Supply Chain's performance measurement. Delivery costs will arise when some 
items are delivered. Change in delivery cost depends on distance, transportation mode, and the fraction of delivery cost. According to Sterman [13], inventory cost is calculated at the end of the month, and if the suppliers cannot fulfill customers' orders. Change in inventory cost depends on the number of stock and fraction of inventory cost. All scenarios are using the same stock and flow diagram for cost performance described in Figure 6.

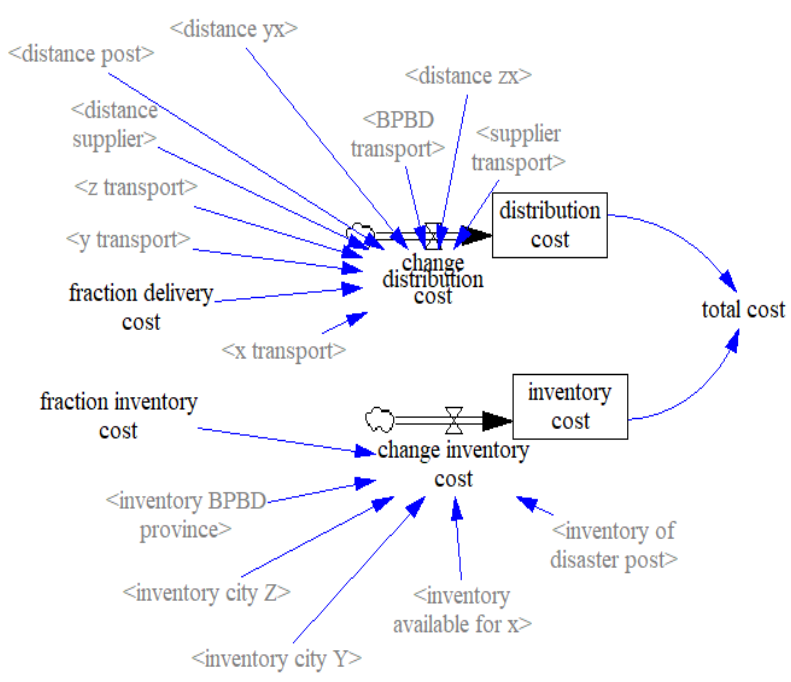

Figure 6. Stock and flow diagram of cost performance

Performances are simulated on stock and flow diagrams based on two scenarios for both type of products. The scenarios run for the model described in Table 2.

All scenarios run for current system and partnership system on simulation. The first scenario is needed to ensure it could be responsive when the demand arises. The second scenario is when the demand jumped on the period of 72 . The second scenario is needed to ensure the model can overcome the dynamic problem of demand in the humanitarian supply chain. To develop the second scenario, some variables are added to the model that could make the demand arise suddenly at a specific time.

\section{Results and Discussions}

\section{Performance Comparison}

Cost, distribution lead time, and bullwhip effect are the performance measurement parameters used in this study, as suggested by Beamon et al. [2] and Sterman [13]. We consider the distribution and inventory costs.

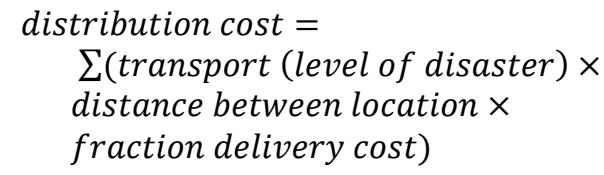

inventory cost $=\sum($ the amount of inventory $\times$
fraction inventory cost $)$

total cost $=$ distribution cost + inventory cost

Equation (1) is provided to obtain the distribution cost, while equation (2) is provided to obtain the inventory cost. The transport parameter is the conditional function of the level of disaster. If the level of disaster is 0 , there will be no delivery between location and vice versa.

Bullwhip effect performance could be calculated by obtaining the Bullwhip Effect Index (BEI). BEI more than 1 indicates that the subject is contributing to the bullwhip effect, vice versa. Expression (4) is provided to obtain the Bullwhip Effect Index (BEI).

$B E I=\frac{\text { variance of total outgoing order }}{\text { variance of total incoming order }}$

As the result of the simulation, the amount of inventory in BPBD province and disaster posts for the proposed system is lower than the current system. Besides, the number of victims' needs can be met more quickly on the proposed system. The performance comparison between the current system simulation and partnership system simulation for the first scenario is described in Table 3. Meanwhile, the performance comparison between the current and partnership system for the second scenario could be seen in Table 4.

Table 3. Discrepancy Current and Partnership for the First Scenario

\begin{tabular}{|c|c|c|c|}
\hline \multirow{2}{*}{\multicolumn{2}{|c|}{ Performance Measurement }} & \multicolumn{2}{|c|}{ Productivity per Scenario } \\
\hline & & $\mathrm{F} 1$ & $\mathrm{~B} 1$ \\
\hline \multicolumn{2}{|c|}{ Time to Fulfil Demand } & $27 \%$ & $43 \%$ \\
\hline \multirow{3}{*}{ Cost } & Distribution & $77 \%$ & $94 \%$ \\
\hline & Inventory & $19 \%$ & $0.5 \%$ \\
\hline & TOTAL & $53 \%$ & $85 \%$ \\
\hline \multirow{3}{*}{$\begin{array}{l}\text { Bullwhip } \\
\text { effect index }\end{array}$} & $\begin{array}{l}\text { Inventory of } \\
\text { BPBD province }\end{array}$ & $-63 \%$ & $-54 \%$ \\
\hline & $\begin{array}{l}\text { Inventory of } \\
\text { disaster post }\end{array}$ & $0 \%$ & $0 \%$ \\
\hline & Backlog & Eliminated & Eliminated \\
\hline
\end{tabular}

Table 4. Discrepancy Current and Partnership for the Second Scenario

\begin{tabular}{clrr}
\hline \multirow{2}{*}{ Performance measurement } & \multicolumn{3}{c}{ Productivity per Scenario } \\
& F2 & B2 \\
\hline \multicolumn{2}{c}{ Time to fulfil the 1st demand } & $27 \%$ & $43 \%$ \\
Time to fulfil the 2 ${ }^{\text {nd }}$ demand & $-5 \%$ & $2 \%$ \\
\hline \multirow{2}{*}{ Cost } & Distribution & $24 \%$ & $35 \%$ \\
& Inventory & $-6 \%$ & $-34 \%$ \\
& TOTAL & $13 \%$ & $29 \%$ \\
\hline \multirow{2}{*}{ Bullwhip } & Inventory of & & \\
Effect Index & BPBD Province & $-67 \%$ & $-51 \%$ \\
& Inventory of & & \\
& Disaster Post & $-29 \%$ & $-35 \%$ \\
& Backlog & Eliminated & Eliminated \\
\hline
\end{tabular}


The graphical result for each scenario is presented in Figure 7(a) for the current system of the first scenario, 7(b) for the partnership system of the first scenario,7(c) for the current system of the second scenario, and 7(d) for the partnership system of the second scenario.

In Table 3, in the first scenario (F1 and B1), based on simulation, it is revealed that the time to fulfill demand and cost can be reduced by implementing partners in the emergency response phase. Time to fulfill demand is counted when the inventory of disaster post is enough to fulfill the demand. The percentage number shown in the table indicate the ratio of productivity (if positive) or waste (if negative) with the current value of time and cost. For the BEI, a negative percentage means that the proposed system's BEI is larger than the current system, vice versa. The total distribution time's decrement is about $43 \%$ for the blanket and $27 \%$ for the food package. Meanwhile, $85 \%$ of the total cost for blankets can be reduced and $53 \%$ for food packages. There is no backlog of inventory on both scenarios' partnerships system, whereas there is a backlog in the current system.

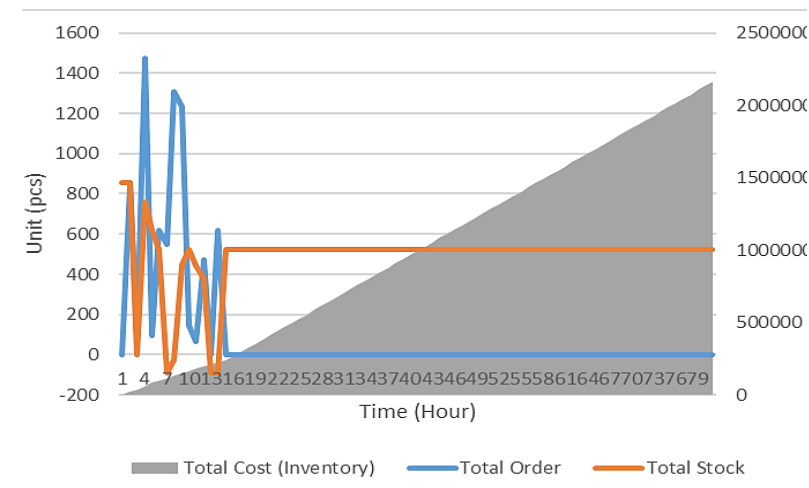

(a)

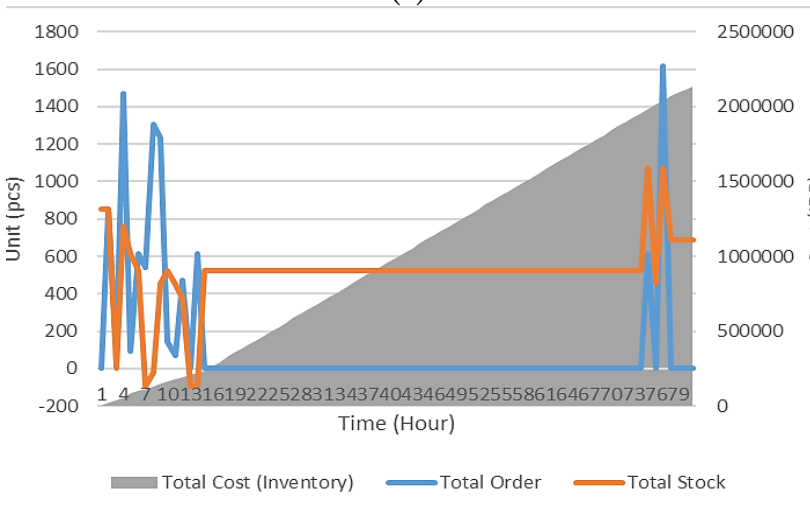

(c)
By Table 3 and Table 4, productivity or performance increments are expected to happen in the food package or blanket. However, the system is unable to create increment from the bullwhip effect index. In the first scenario, the proposed system generates, on average, $69 \%$ cost savings for food packages and for blankets, while the time to distribute the aids had decreased $35 \%$ on average.

The increment of productivity in both types of product may happen because demand information is transferred faster in the partnership model (see Figure 8b and 8d). As an effect, the delay order between parties is reduced, which means the uncertainty becomes minor. This phenomenon is analogous to an occurrence in business logistics [26]. The backlog is eliminated in both scenarios, but it is seen in Table 3 that the bullwhip effect index is increasing on the partnership system. It can happen because the supply chain system is highly responsive to the demand for the partnership system. Suppliers directly send a large number of items to BPBD Province as soon as they get the information about victim needs. It makes the variance figure of in and out stock is larger than the current system.
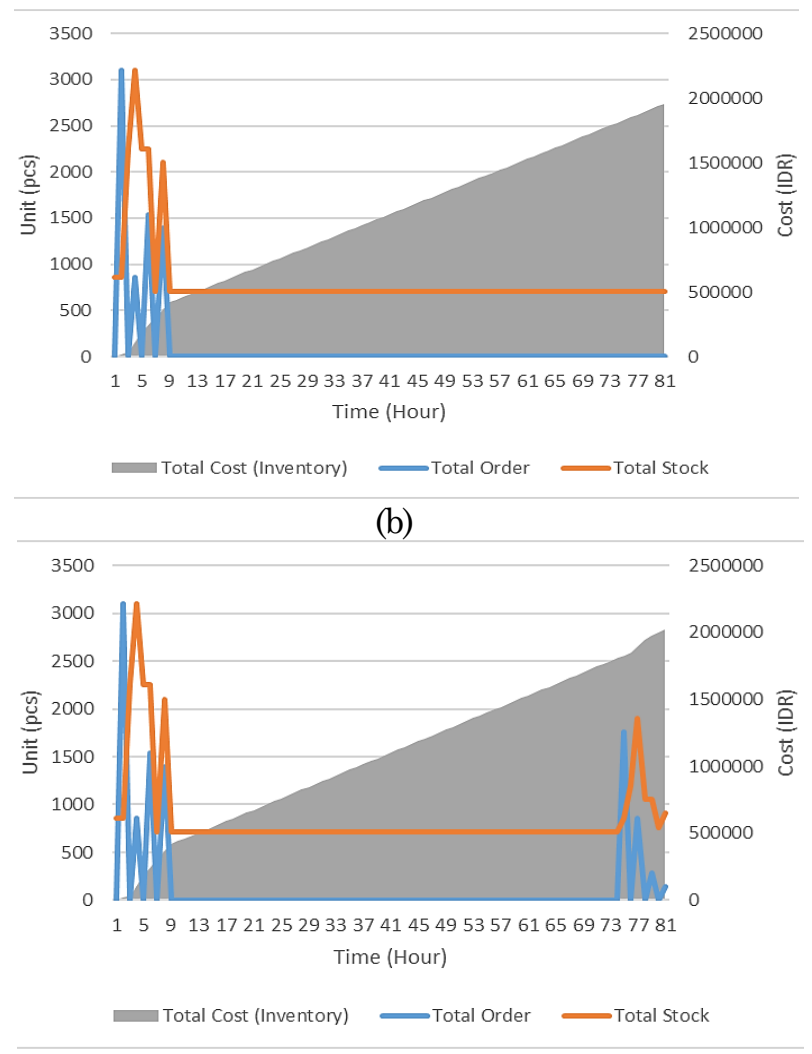

(d)

Figure 7. Comparison Graph of Timeline Total Performance (a) Current Practice $1^{\text {st }}$ Scenario (b) Partnership System $1^{\text {st }}$ Scenario (c) Current Practice $2^{\text {nd }}$ Scenario (d) Partnership System $2^{\text {nd }}$ Scenario 
In Table 4, on the jumped demand scenario (F2 and B2), it is revealed that the time to fulfill demand and total cost also can be reduced. Time to fulfill the first demand can be reduced by $27 \%$ for food package scenario and $43 \%$ for blanket scenarios. There are about $13 \%$ inventory cost savings for food scenarios and $29 \%$ inventory cost savings for blanket scenarios. There is no backlog of inventory, but the inventory cost is no longer reduced, as shown in Table 3 (scenario 1). Time to fulfill the $2^{\text {nd }}$ demand in the second scenario for food package distribution also increases (performance decrements 5\%). It might happen because when there is an unexpected demand, the supply chain system should restock their inventory as soon as possible in order to fulfill the demand. Figure $8 d$ shows that when the jump in demand happens, the system could quickly provide some items on the first demand but not on the second demand. Surges in second demand can be tempered because of sufficient inventory, so the second distribution is delayed until $\mathrm{t}=81$.

\section{Discussion}

The stock and flow diagram build to mimic the disaster relief replenishment system in Indonesia. The relationship of all parties involved in the supply chain is described fully in Figures 2 and 3. We may perceive the role of regional government as a budget controller, supplier of goods, BPBD as a province or district coordinator, and independent donors. The form of the partnership system proposed in this study is sharing demand and inventory across partners, as in Figure 6, sharing information practices is exposed by eliminating orders placed from the downstream supply chain. Sister companies commonly use this type of partnership through strategic alliance and Vendor Managed Inventory (VMI) processes [27]. In the case of this humanitarian supply chain with lumpy demand, VMI can be used as suggested in Lechtenberg [27], of course, by considering the demands that arise in certain phases of the disaster management process. The proposed type of partnership itself had become standard practice in regular business [24] and recently had grown in the application of humanitarian logistics [28]. This article, however, emphasizes the importance of such relationships in the disaster relief process. The operational partnership model can be obtained with technology-savvy such as blockchain [25] even though some infrastructure barriers may challenge, especially in the geographical disaster condition. However, with the growth of the mobile internet, the possibility is still wide open.

Based on the simulation result, the cost and time performance are enhanced by the partnership system. This result is in line with Heaslip [4], which stated that partnership between two parties improves supply chain performances. The partnership system simulation is confirmed to generate an improved impact on disaster relief logistic systems because every demand could be fulfilled as soon as possible. In practical terms, the proposed partnership system warrants the suppliers' readiness to satisfy the demand. Coupled with blockchain, operation activities' performance during seven days of disaster relief shall be increased [25].

The flow process diagram (as depicted in Figure 2) and stock and flow diagram (Figure 5 and Figure 6) are built on the assumption of beer game simulation, where every participant on the supply chain system is depicted. The models described how the system attempted to fulfill the demand from the victim by doing coordination. Coordination on this supply chain system is depicted by the flow of information and flow of material between parties such as suppliers, regional disaster management, disaster emergency post, and others. Validation is done by comparing the patterns depicted in the simulation results. The bullwhip effect pattern on stocks (Figure 8) is similar to the beer distribution game's bullwhip effect pattern in which the orders will increase when stocks are few [13].

Performance measurements on beer game simulation, such as bullwhip effect and backlog [13], are also measured in this research (Table 3 and Table 4). There is an unexpected result of the bullwhip effect index, which is higher than the current system. The higher index happens as the effect of responsiveness designated to overcome disaster victim's need. The responsiveness is seen in the different order pattern between the current practice and the partnership system (Figure 7). In current practice, new orders will be executed when a location experiences a stockout without considering replenishing the safety-net inventory in each city in the system. Meanwhile, in a partnership system (Figure $7 \mathrm{~b}$ and $7 \mathrm{~d}$ ), once the number of victims is calculated, orders are made to several parties. Thereby, a large quantity of orders happens in the beginning of the disaster relief process as an impact of fulfilling the demand of victims as well as building the safety-net inventory. This condition is in line with the argument of Zhao et al. [29] that the bullwhip effect will increase when customers' dependence on the suppliers' act since we know that in the disaster relief case, the victim's life depends on how much the aids and how long the supplier could deliver aids. As suggested by Khazraji et al. [30], the bullwhip effect could be minimized by determining appropriate inventory policies. These policies could be a control system of the flow and the stock of materials. As a managerial implication, National Disaster Management has some research on their policies about stock and flow of aids during the emergency response phase and could be future potential research. This 
research is limited to the generated data collected only from West Java's Regional Disaster Management for food and blanket; therefore, it is suggested to use the actual data (non-generated data) for the implementation in the real case.

However, this research has some limitations on the validation. The user's description is used in developing this research, as suggested through inside us point of view [31]. This method is acknowledging the cognitive bias of users. However, field observation to overcome the bias is restricted and unable to be done. Besides, the scope of model is only for Regional Disaster Management and doesn't consider stock and cost of supplier. Therefore, any differences with real conditions are a limitation in this study that needs to be strengthened or overcome in further research.

\section{Conclusions}

This paper had demonstrated by dynamic system simulation that the improvement of Indonesia's disaster relief replenishment system can be gained by building partnership systems between suppliers, national disaster agencies, and regional disaster agencies. Based on the simulation, the performances (bullwhip effect, backlog, and total supply chain cost) for two developed scenarios show the improvement system behavior and dynamics of each type of replenishment strategy. Based on the performance, it is known that the implementation of a partnership strategy, which is reflected by the partnership scenario, shows better performance in the backlog and total supply chain cost and has a robust result against the different types of product replenishment. There is no backlog on partnership scenarios that make sure that every demand is always fulfilled.

This result indeed brings a foundation for the disaster management practice to more in-depth to examine the different partnerships that benefit the disaster phase's operations phase. As an implication of the increment of disaster relief supply chain, it is suggested to emphasize the design of the partnership's tactical and operational details to increase efficiency yet the security of the replenishment system, which is vital in the era of industrial 4.0.

This research shall be followed by determining optimum operational decisions such as routing, replenishment size, or risk management for disaster relief concerning the blockchain implementation.

\section{Acknowledgement}

The authors would like to thank the Regional Disaster Management Authority (Badan Penanggulangan Bencana Daerah) of West Java to validate the causal loop diagram and stock and flow model.

\section{References}

1. Thomas, A. and Kopczak, L.R. From Logistics to Supply Chain Management: The Path Forward in the Humanitarian Sector, 2005, Fritz Institute, San Francisco, CA.

2. Beamon, B.M., and Balcik, B., Performance Measurement in Humanitarian Relief Chains. International Journal of Public Sector Management, 21(1), 2008, pp. 4-25.

3. Arminas, D., Supply Lessons of Tsunami Aid, Supply Management, 10 (2), 2005, p. 14.

4. Heaslip, G., Case Study Partnerships - Supply Chain Strategy, in Haavisto, I., Kovács, G., Spens, K., (Eds.), Supply Chain Management for Humanitarians, 2016, pp. 89-99.

5. Tomasini R. M., Partnerships and Innovative Procurement as Enablers for Sustainable Development Goals., in Haavisto, I., Kovács, G., Spens, K. (Eds.), Supply Chain Management for Humanitarians, 2016, pp. 182-188.

6. Comes, T., and Walle, B., Information Systems for Humanitarian Logistics., in Haavisto, I., Kovács, G., Spens, K., (Eds.), Supply Chain Management for Humanitarians, 2016, pp. 182188.

7. Angulo, A., Nachtmann, H. and Waller, M.A. Supply Chain Information Sharing in a Vendor Managed Inventory Partnership, Journal of Business Logistics, 25(1), 2004, pp. 101-120.

8. Waller, M.A., Johnson, M.E. and Davis, T. Vendor-managed Inventory in the Retail Supply Chain, Journal of Business Logistics, 20 (1), 1999, pp. 183-203.

9. Nakasumi, M. Information Sharing for Supply Chain Management based on Block Chain Technology, Faculty of Economics, 2017, Komazawa University, Tokyo

10. Lodree, E. Pre-storm Emergency Supplies Inventory Planning, Journal of Humanitarian Logistics and Supply Chain Management, 1(1), 2011, pp. 50-77.

11. Habib, M. S., Lee, Y. H., and Memon, M. S. Mathematical Models in Humanitarian Supply Chain Management: A Systematic Literature Review, Department of Industrial and Management Engineering, 2015, Hanyang University, Republic of Korea.

12. Iakovou, E., Vlachos D., Keramydas C., and Partsch, D. Dual Sourcing for Mitigating Humanitarian Supply Chain Disruptions, Journal of Humanitarian Logistics and Supply Chain Management, 4 (2), 2014, pp. 245 - 264.

13. Sterman, J. Business Dynamics: Systems Thinking and Modelling for a Complex World, New York: McGraw-Hill, 2000.

14. Bimantio, M.P. System Dynamic Simulation of Salacca-Pondoh's Business as Usual Condition in Sleman District, Yogyakarta Province, 
Indonesia, Jurnal Teknik Industri, 21 (1), 2019, pp. 25-32.

15. Akhlaghinia, N., Ghatari, A.R., Moghbel A., Yazdian A. Developing a System Dynamic Model for Pharmacy Industry, International Journal of Industrial Engineering and Management Systems, 17 (4), 2018, pp. 662-668.

16. Yuliawati, E., Hadiwardoyo, S.P., Susantono, B., Tjahjono, T. System Dynamics Model for Airport Characterization in Hub-and-Spoke Networks, International Journal of Technology, 6(5), 2015, pp. 733-742.

17. Besiou, M., Stapleton, O., Van Wassenhove, L. N. System Dynamics for Humanitarian Operations, Journal of Humanitarian Logistics and Supply Chain Management, 1 (1), 2011, pp. 78- 103.

18. Wismabrata, M. H., 6 Fakta Terbaru Gempa Lombok, Kekurangan Air Bersih Hingga Pembangunan Rumah Korban. Retrieved from https://regional.kompas.com/read/2018/08/27/13 232461/6-fakta-terbaru-gempa-lombokkekurangan-air-bersih-hingga-pembangunanrumah, 2018

19. Safutra, I., Mereka Butuh Terpal dan Air Bersih. Retrieved from https://www.jawapos.com/ features/humaniora/21/08/2018/dilemapenyaluran-bantuan-untuk-korban-gempalombok/, 2018

20. Reyes, L. F., and Andersen, D. L. Collecting and Analyzing Qualitative Data for System Dynamics: Methods and Models, System Dynamics Review, 16(4), 2003, pp. 271-296.

21. Senge, P.M., The Fifth Discipline: The Art and Practice of the Learning Organization, 1994, Doubleday, New York, NY.

22. Kim, D. H., System Thinking Tools: A User's Reference Guide, 1994, Pegasus Communication, Inc.

23. Zakery, A., Afrazeh, A. and Dumay, J., Analysing and Improving the Strategic Alignment of Firms'
Resource Dynamics, Journal of Intellectual Capital, 18 (1), 2017, pp. 217-240.

24. Cooke, D., Rohleder, T. and Rogers, P., A Dynamic Model of the Systemic Causes for Patient Treatment Delays in Emergency Departments, Journal of Modelling in Management, 5 (3), 2010, pp. 287-301.

25. Ariningsih, P.K., and Sundara, G.Y., Blockchain for Improvement of Emergency Response in Humanitarian Logistics Indonesia. $9^{\text {th }}$ Operations and Supply Chain Management Conference, Ho Chi Minh City, December 2019.

26. Ariningsih, P.K., Tan, A., and Susanto, S., Aid Replenishment Strategy during Demand Increment on Humanitarian Logistic Relief, International Journal of Simulation: System, Science and Technology, 19(1), 2018

27. Hogarth Scott, S., Retailer Supplier Partnerships: Hostages to Fortune or the Way Forward for the Millennium, British Food Journal, 101(9), 1999, pp. 668-682.

28. Letcherberg, S., Widera, A., and Hellingrath, B., Assessing Vendor Managed Inventory for Humanitarian Organizations, 14th International Conference on Information Systems for Crisis Response and Management, 2017, At Albi, France

29. Zhao, R., Mashruwala, R., Pandit, S. and Balakrishnan, J., Supply Chain Relational Capital and the Bullwhip Effect: An Empirical Analysis using Financial Disclosures, International Journal of Operations and Production Management, 39 (5), 2019, pp. 658-689

30. AL-Khazraji, H., Cole, C., and Guo, W., Dynamics Analysis of a Production-inventory Control System with Two Pipelines Feedback, Kybernetes, 46 (10), 2017, pp. 1632-1653

31. Daellenbach, H. G., and McNickle, D. C. Management Science: Decision Making through Systems Thinking. New York: Palgrave Macmillan, 2005. 